\title{
Article
}

\section{The Genetics of Human DZ Twinning}

\author{
Dorret I. Boomsma \\ Netherlands Twin Register, Vrije Universiteit, Amsterdam, The Netherlands
}

\begin{abstract}
In the course of twin studies whose main focus was elucidation of genetic and environmental factors on behavioral traits, many twin researchers became aware of the strong tendency for dizygotic (DZ) twinning to run in families. Over four decades, Nick Martin and others initiated hormone and ultrasound studies, performed segregation and pedigree analyses, tested candidate genes, carried out linkage projects in sister pairs and formed large collaborations to illuminate the genetics of DZ twinning by genome-wide association studies and meta-analysis. This article summarizes the early work on hormone and genetic studies and describes the meta-analyses that have at last met with success in finding the first genes that predispose to DZ twinning, which also appear to influence many other female reproductive traits.
\end{abstract}

Keywords: DZ twinning; multiple ovulation; GWAS; genetics

(Received 17 February 2020; accepted 30 March 2020; First Published online 8 May 2020)

Twin researchers like Nick Martin, who love twins for the power of the classical twin design, who work with twin data, recruit twins into their studies, and interact with twins and their relatives, become inspired not only by the data they collect but also by the questions they are asked by twin families. Nick started his first twin study, on scholastic ability, around 1970 from his parental home in Adelaide. He received help from his father, Peter Martin, an influential geneticist with whom he published the results of this investigation (Martin, 1975; Martin \& Martin, 1975). Later, in 1978, while a postdoc in Canberra, he began the Australian Twin Registry (ATR). His mother, Beryl Martin, a well-known painter of watercolors supplied the 'thank you' cards for twins who registered for the first ATR studies of alcohol metabolism, finger ridge count and, in one of the first discordant-twin design studies, vitamin $\mathrm{C}$ and the common cold (Martin et al., 1982).

Early on, Nick Martin was confronted by questions from mothers of twins wanting to know 'which set of their twins' he wished to study, why twins seem so plentiful in their family and - most pressing - what the recurrence risk might be of their having another set of twins. It would take nearly 40 years to answer some of their questions. Over these four decades, Nick and others initiated hormone and ultrasound studies, performed segregation and pedigree analyses, tested candidate genes, carried out linkage projects in sister pairs and formed large collaborations to illuminate the genetics of dizygotic (DZ) twinning by genome-wide association studies (GWAS) and meta-analysis. Monozygotic (MZ) twinning was thought to be a 'random' event, whereas DZ twinning clearly had a strong familial component (Bulmer, 1970). DZ twins result from the fertilization of two or more follicles released at ovulation after processes of follicle growth and selection, and this sequence of events can be influenced by genetic factors at each step.

Author for correspondence: Dorret Boomsma, Email: di.boomsma@vu.nl

Cite this article: Boomsma DI. (2020) The Genetics of Human DZ Twinning. Twin Research and Human Genetics 23: 74-76, https://doi.org/10.1017/thg.2020.15
Martin et al. published a first hormone study in 1984, and for this project, 14 women were recruited, eight of whom had at least one set of DZ twins (six with two sets) and six parous women without DZ twins. Blood draws were at fixed days of their natural cycle, as the hypothesis of interest was that the tendency to have DZ twins is associated with higher follicle-stimulating hormone (FSH) levels in the early follicular phase. Other hormones, including luteinizing hormone (LH), were also assessed. Early FSH and to a lesser extent, LH levels were, at the $10 \%$ significance level, higher in mothers of twins.

In a next paper published in 1991, the number of days for taking blood samples increased from 3 to 5 days and eight mothers of DZ twins and eight matched controls were recruited. Except for one blood draw, all blood samples were taken in the women's homes. Martin, Robertson et al. (1991) set out to test whether multiple ovulation in DZ-twin mothers was because of higher hypothalamic stimulation or whether it was in response to lower serum levels of ovarian inhibin. In this study, FSH levels were again elevated, although not significantly different between the two groups, but $\mathrm{LH}$, inhibin and estradiol levels were elevated on multiple days, suggesting that the primary cause of multiple ovulation is not associated with lower inhibin levels.

Endocrine studies have demonstrated that gonadotrophin release from the hypothalamic-pituitary system is pulsatile. This is observed most strongly for LH release with the signal carried primarily by the frequency of pulses. FSH release is also pulsatile, so measuring only differences in mean FSH levels may miss effects of changing pulse frequency. In the Netherlands, Lambalk et al. (1998) confirmed the earlier endocrine findings for DZ twinning by Nick Martin that women bearing DZ twins have elevated FSH concentration and showed that this increase is particularly associated with a rise in the FSH pulse frequency. These observations were made after serial blood samples were taken every $10 \mathrm{~min}$ for a period of $6 \mathrm{~h}$. Immediately after the last sample, women also received an $\mathrm{LH}$-releasing hormone challenge.

(c) The Author 2020. Published by Cambridge University Press. This is an Open Access article, distributed under the terms of the Creative Commons Attribution licence (http:// creativecommons.org/licenses/by/4.0/), which permits unrestricted re-use, distribution, and reproduction in any medium, provided the original work is properly cited. 
The 1991 hormone study also looked at whether multiple ovulation occurred in the cycle under study by using ovarian ultrasonography on day 12 of the menstrual cycle. Two mothers of DZ twins had more than one follicle. The ultimate ultrasound study was published in the same year (Martin, Shanley et al., 1991), in Acta Geneticae Medicae et Gemellologiae, the predecessor of Twin Research and Human Genetics. The year-long study followed 21 mothers of DZ twins and 18 controls and firmly established multiple large follicle growth, both ipsi- and contralateral, in the twin mothers, but not in the controls.

In 1996, the Australian, East-Flanders and Netherlands Twin Registers, in collaboration with Cathryn Lewis who then was at the University of Utah in Salt Lake City, attempted to apply complex segregation analysis to determine whether there was evidence for a major gene underlying the tendency to have DZ twins. Large series of pedigrees with mothers of $\mathrm{DZ}$ twins as probands were analyzed, and the inheritance of $\mathrm{DZ}$ twinning was confirmed in these multigeneration data, with paternal as well as maternal inheritance, a low penetrance and limited or no evidence for major gene effects or X-linked inheritance (Lewis et al., 1996; Meulemans et al., 1996).

Multiple publications on human twinning refer to strong animal models for DZ twinning, especially to the work done in sheep. Maybe naively, at the time when candidate gene studies were feasible, it was thought that the well-characterized loci leading to multiple ovulation in, for example, Booroola merino ewes, would hold the key to unraveling multiple ovulation in humans. This led to a long-lasting collaboration with Grant Montgomery who had pioneered the sheep studies, multiple studies of candidate genes and a large linkage study in affected sister pairs. The linkage study (Painter et al., 2010), which included affected sister pairs (at least two sisters who were both mothers of spontaneous DZ twins) from over 500 families from Australia, New Zealand and some large pedigrees from Utah and the Netherlands did not observe any linkage peaks with LOD scores above 3 (LOD stands for logarithm of the odds with LOD scores of 3 or higher indicating the odds are a thousand to one that a trait gene is linked to a genetic marker). In the end concluded that the data provided further evidence for complex inheritance of familial DZ twinning.

Early studies of candidate genes included, for example, the protease inhibitor locus on chromosome 14, which encodes alpha 1 -antitrypsin protein. The locus is highly polymorphic, and some of its minor alleles, referred to as Z- and S-alleles, have repeatedly been found to be associated with DZ twinning (Boomsma et al., 1992; Clark \& Martin, 1982;Lieberman et al., 1979), but these findings still await replication in GWAS. Most of the work on candidate genes was summarized by Gajbhiye et al. (2018) in a review paper that concluded that we are still far away from resolving the genetics on DZ twinning, as rare and low-frequency variants, in for example, BMP15 and BMPR1B, accounted for only a tiny fraction of variation in $\mathrm{DZ}$ twinning.

In the search for common genetic variants that could explain the inheritance of DZ twinning, a new approach became feasible when genetic variation could be quantified at a large scale using single-nucleotide polymorphism (SNP) arrays. Hamdi Mbarek, working with the Netherlands Twin Register in Amsterdam, was courageous enough to analyze the data from 1980 mothers of spontaneous DZ twins and 12,953 controls. These numbers seemed small in comparison to those in increasingly large genome-wide association meta-analyses for other complex traits that needed samples 10 - or 20-fold larger to find any significant hits. Sample sizes in the Mbarek et al. study initially were a bit larger, but the first analyses did not detect much signal in the data. However, this result quite dramatically changed after rigorous cleaning of the phenotype data to remove $\sim 100$ mothers who had conceived their twins after using assisted reproductive techniques, such as in vitro fertilization, and also removing controls who reported DZ twinning in their pedigrees. The study identified, and replicated in the deCODE Icelandic databases, an association with DZ twinning for SNPs close to Follicle-Stimulating Hormone Beta Subunit $(F S H B)$ and in SMAD Family Member 3 (SMAD3) providing support for Nick's early studies on FSH concentrations in mothers of DZ twins. The risk alleles close to FSHB and in SMAD3 increased the frequency of twin births in the Icelandic population by $18 \%$ and $9 \%$, respectively (Mbarek, Steinberg et al., 2016). FSH genes had always been strong candidates for DZ twinning, but the finding for SMAD3 on chromosome 15 was new. The lead SNP associated with DZ twinning maps to the first intron in SMAD3 and is strongly expressed in the human ovary, where it promotes granulosa cell proliferation and steroidogenesis. The region of chromosome 15q22.33 also includes SMAD Family Member 6 (SMAD6), and we cannot rule out its involvement. SMAD3 and SMAD6 are components of the transforming growth factor- $\beta /$ bone morphogenic protein signaling system. This region was found to be equivalent to genomic region on bovine chromosome 10 (the location of both SMAD3 and SMAD6), which is associated with increasing ovulation rate and twinning in cattle (Kamalludin et al., 2018; Kirkpatrick \& Morris, 2015).

Efforts to localize and characterize the genes for DZ twinning, and now also for MZ twinning, which we for a long-time thought to have no genetic basis, continue. At the December 2017 meeting of the International Society for Twin for Studies in Madrid, the next sets of results for DZ twinning showed a sharp increase in the number of significant hits and a more recent meeting to discuss progress in November 2019 in Singapore presented new findings that promise exciting novel insights into the etiology of not only DZ but also MZ twinning. We should continue to translate such findings to our twin participants and to mothers of twins in everyday language. Based on the findings of the 2016 paper, Mbarek, Dolan et al. (2016) proposed to present the effects for the combined effects of FSHB and SMAD3 as follows: 'In the Dutch population the probability of spontaneous DZ twinning is 10.7 per 1000 births. If the risk alleles were absent, this would be 7.76 per 1000 births. If all females carried all four risk alleles, this would be 12.71 per 1000 births' (p. 419). Such translations do not yet address the risk of having twins at an individual level, but larger studies may make this a feasible option in future.

\section{References}

Boomsma, D. I., Frants, R. R., Bank, R. A., \& Martin, N. G. (1992). Protease inhibitor (Pi) locus, fertility and twinning. Human Genetics, 89, 329-332.

Bulmer, M.G. (1970). The biology of twinning in man. Oxford: Clarendon.

Clark, P., \& Martin, N. G. (1982). An excess of the Pi S allele in dizygotic twins and their mothers. Human Genetics, 61, 171-174.

Gajbhiye, R., Fung, J. N., \& Montgomery, G. W. (2018). Complex genetics of female fertility. NPJ Genomic Medicine, 3, 29.

Kamalludin, M. H., Garcia-Guerra, A., Wiltbank, M. C., \& Kirkpatrick, B. W. (2018). Trio, a novel high fecundity allele: I. Transcriptome analysis of granulosa cells from carriers and noncarriers of a major gene for bovine ovulation rate. Biology of Reproduction, 98, 323-334.

Kirkpatrick, B. W., \& Morris, C. A. (2015). A major gene for bovine ovulation rate. PLoS One, 10, e0129025.

Lambalk, C. B., Boomsma, D. I., de Boer, L., de Koning, C. H., Schoute, E., Popp-Snyders, C., \& Schoemaker, J. (1998). Increased levels and pulsatility 
of follicle-stimulating hormone in mothers of hereditary dizygotic twins. Journal of Clinical Endocrinology and Metabolism, 83, 481-486.

Lewis, C. M., Healey, S. C., \& Martin, N. G. (1996). Genetic contribution to DZ twinning. American Journal of Medical Genetics, 61, 237-246.

Lieberman, J., Borhani, N. O., \& Feinleib, M. (1979). alpha1-Antitrypsin deficiency in twins and parents-of-twins. Clinical Genetics, 15, 29-36.

Martin, N. G. (1975). The inheritance of scholastic abilities in a sample of twins. II. Genetical analysis of examinations results. Annals of Human Genetics, 39, 219-229.

Martin, N. G., Carr, A. B., Oakeshott, J. G., \& Clark, P. (1982). Co-twin control studies: Vitamin $\mathrm{C}$ and the common cold. Progress in Clinical and Biological Research, 103, 365-373.

Martin, N. G., \& Martin, P. G. (1975). The inheritance of scholastric abilities in a sample of twins. I. Ascertainments of the sample and diagnosis of zygosity. Annals of Human Genetics, 39, 213-218.

Martin, N. G., Olsen, M. E., Theile, H., El Beaini J. L., Handelsman, D., \& Bhatnagar, A. S. (1984). Pituitary-ovarian function in mothers who have had two sets of dizygotic twins. Fertility and Sterility, 41, 878-880.

Martin, N. G., Robertson, D. M., Chenevix-Trench, G., de Kretser, D. M., Osborne, J., \& Burger, H. G. (1991). Elevation of follicular phase inhibin and luteinizing hormone levels in mothers of dizygotic twins suggests nonovarian control of human multiple ovulation. Fertility and Sterility, 56, 469-474.

Martin, N. G., Shanley, S., Butt, K., Osborne, J., \& O’Brien, G. (1991). Excessive follicular recruitment and growth in mothers of spontaneous dizygotic twins. Acta Geneticae Medicae et Gemellologiae, 40, 291-301.

Mbarek, H., Steinberg, S., Nyholt, D. R., Gordon, S. D., Miller, M. B., McRae, A. F., Boomsma, D. I. (2016). Identification of common genetic variants influencing spontaneous dizygotic twinning and female fertility. American Journal of Human Genetics, 98, 898-908.

Mbarek, H., Dolan, C. V., \& Boomsma, D. I. (2016). Two SNPs associated with spontaneous dizygotic twinning: Effect sizes and how we communicate them. Twin Research and Human Genetics, 19, 418-421.

Meulemans, W. J., Lewis, C. M., Boomsma, D. I., Derom, C. A., van den Berghe, H., Orlebeke, J. F., Vlietinck, R. F., \& Derom, R. M. (1996) Genetic modeling of dizygotic twinning in pedigrees of spontaneous dizygotic twins. American Journal of Medical Genetics, 61, 258-263.

Painter, J. N., Willemsen, G., Nyholt, D., Hoekstra, C., Duffy, D. L., Henders, A. K., Montgomery, G. W. (2010). A genome wide linkage scan for dizygotic twinning in 525 families of mothers of dizygotic twins. Human Reproduction, $25,1569-1580$. 